of knowledge which can only be acquired by long years of patient study. If there is one lesson to be learnt from the history of fisheries research-one that cannot be too heavily stressedit is that the opportunity of dealing effectively with a fishery problem will generally be lost unless this basic knowledge has been obtained in advance and is ready for application. Even in our home waters, which have been examined so long and so closely, our information is not within sight of being complete : in almost every branch of fisheries work there are new fields to be explored, new methods to be tried and many large gaps in the knowledge we possess. But it may at least be said that we have made a beginning. In many other parts of the world not even a beginning has yet been made ; ignorance is profound and there is no background of knowledge which can be utilized.

It is surely time that the importance of such knowledge was recognized and that early steps were taken to lay the foundations of fishery science throughout the Empire.

\title{
International Standard of Musical Pitch
}

\author{
By Dr. G. W. C. Kaye, O.B.E.
}

THE problem of the international standard.

1 ization of musical pitch has recently assumed a new prominence in view of the increasing exchange of concert and similar programmes by the various broadcasting organizations in different countries. The general question has come up from time to time in the past, though it cannot be said that any substantial measure of unification has ever resulted internationally.

The history of musical pitch is one of many 'standards', mainly evolved by some body of standing, which at the time was able to impose its will to a greater or less extent on current practice. In some countries, indeed, the choice of pitch was, and still is, enforced by legal decree. It has long been customary to express musical pitch in terms of the frequency of the note $A$ in the treble clef; and this convention will be observed in what follows.

Ellis (J. Roy. Soc. Arts, 1880) gives us a good notion of the state of affairs which prevailed in the early history of musical pitch. It appears that from the fourteenth to the seventeenth century, the note A wandered haphazardly over a range of nearly 200 cycles per second ( 374 to 567 ). In the eighteenth century, the upper limit came down by more than 100, the spread of pitch being from 377 to about 423. During the nineteenth century the range was from about 424 to 494 , a progressive rise being evident up to about 1887, reflecting no doubt, as always, a striving for increased brilliancy.

In Great Britain, the London Philharmonic Orchestra was the premier orchestra for many years, and the philharmonic pitch was followed by most other orchestras, being first based in $\mathbf{1 8 2 6}$ on a value of $\mathbf{4 3 3}$ for $A$, and afterwards (nineteen years later) on 455 . A conference of physicists at Stuttgart in 1834 adopted 440 , while a similar conference of musicians and physicists appointed by the French Government in 1859, established the 'Diapason Normal', which was based on a figure of 435 (largely through the influence of Koenig), the associated temperature of the instruments being taken as $15^{\circ} \mathrm{C}$. $\left(59^{\circ} \mathrm{F}\right.$.). This pitch, which was legalized in France and had a fairly wide vogue in Europe, was adopted by the Boston Symphony Orchestra at its foundation in 1883, and was endorsed in 1885 by an international congress at Vienna. In 1896, the Philharmonic Society adopted 439 at $68^{\circ} \mathrm{F}$. (see Hipkins, NatUre, Aug. 31, 1899), while in 1899 an international discussion by the pianoforte trade, which revealed values of $A$ ranging from 435 to 442 , also resulted in the adoption of 439 at $20^{\circ} \mathrm{C}$. $\left(68^{\circ} \mathrm{F}\right.$.) by the participating makers, a decision which materially assisted in checking the general tendency of pitch to rise. Another significant step was the lowering in 1927 by the Army Council of the pitch of British Army bands from 455 to 439 at $68^{\circ} \mathrm{F}$.

In the United States, while musical pitch was the subject of many vagaries during the last century, a figure of $\mathbf{4 4 0}$ is now universal, having been adopted by the American Federation of Musicians in 1918, the Music Industries Chamber of Commerce in 1925, and the American Standards Association in 1936. It may be added that this value is in good accord with the usual British figure, as the temperature in American concert halls is said to be customarily of the order of $70^{\circ} \mathrm{F}$.

To come to more recent events, a conference was recently held at Broadcasting House under the auspices of the British Standards Institution, with Dr. G. W. C. Kaye in the chair. The conference was attended by representatives of some thirty musical and other organizations, including the Royal Academy of Music, the Royal College of Music, the Royal College of Organists, the Royal Military School of Music, the Musical Association, 
the British Broadcasting Corporation, the old Vic and Sadler's Wells, the National Physical Laboratory and the federations and associations of manufacturers of wind and string instruments and organ and piano builders. The meeting had also before it the views of eminent conductors and professors of music. After a full discussion, the conference agreed unanimously that the British Standards Institution, as a member of the International Standards Association, should be asked to take action to try to secure an international standard of musical pitch. A small committee, which was appointed to draw up definite proposals, has now commenced its labours.

It emerged from the above meeting that, pending international agreement, the British Broadcasting Corporation has provisionally adopted a figure of 439 for the treble A. It also appeared from radio observations made in Germany that many of the musical performances now broadcast from different countries in Europe are based on a pitch exceeding 435 , being on the average about 443 .

The most recent information available appears to indicate that the accepted figures for $\mathrm{A}$ in most countries lie between 435 and 440 cycles per second, although this range is definitely broadened in actual practice. On the whole, it would seem that if an international figure were to be adopted, it will probably be at or near 440 . The choice of such a figure, which is of course absolute, would be the primary duty of an International Conference.

The next duty, though a secondary one, would be to deal specifically with the temperature question. Many musical instruments, as at present constructed, exhibit appreciable temperature variation of pitch. The majority of the stringed instruments present, of course, no difficulty in this respect, and, as regards the piano, its pitch is stated to fall by only about 1 part in 18,000 for $1^{\circ} \mathrm{F}$. rise in temperature : actually, the effects of humidity changes are probably more significant. In the case of the wind organ, which presents the major problem, the pitch of the flue-pipes rises about 1 part in 500 for $1^{\circ} \mathrm{C}$. rise (that is, about 1 in 1,000 per $1^{\circ} \mathrm{F}$.) for moderate temperature variations. In other words, a pitch of 435 at $15^{\circ} \mathrm{C}$. becomes 439 at $20^{\circ} \mathrm{C}$. The orchestral wind and reed instruments (flute, oboe, clarinet, etc.) are also influenced by the warmth of the breath, fingering, etc. ; they are said to have, on the average, about half the temperature coefficient of the wind organ.

One of the great difficulties with most concert halls is the steady rise of temperature as a concert progresses, so that the pitch of an orchestra may rise by five or more cycles a second during the early stages of a concert. It has been observed in Germany that, after the entry of wind instru. ments which had been kept cold, a sudden shifting of the pitch of an entire orchestra may often result. Thus the concert pitch may be subjected to continual fluctuations during the playing. Improvement may be effected by warming the instruments before a concert to bring them into a steady condition.

The oboe, which is often used as an orchestral standard of pitch, is demonstrably unsatisfactory for the purpose. The piano is clearly better, and a steel tuning fork better still, with a drop in pitch of only about 1 part in 16,000 for $1^{\circ} \mathrm{F}$. rise in temperature. Elinvar forks are even better, with a positive or negative coefficient varying in different samples up to 40 parts in a million. Valve oscillators with mica condensers can be readily constructed which have a temperature coefficient of pitch of less than 1 part in 1,000 .

There are two features which are likely to simplify the temperature question in the future. One is the increasing vogue of air-conditioning, which will make the temperature control of concert halls more feasible. The other is the rapid development of electro-acoustical instruments, such as the electric organ, which have no temperature coefficient, and would appear to present an important field of development. Incidentally, the values adopted for the treble $A$ in two well-known makes of electric organ are 439 and 440 respectively.

It is, of course, appreciated that temperature variation may be especially troublesome under outdoor conditions, which may be extreme in some countries, and it is probably impossible to legislate for such untoward circumstances. Something can be done, it is stated, by pre-tuning the different instruments, for example, in the case of military bands in tropical countries, by flat-piteh tuning of the wind instruments and sharp-pitch tuning of the percussion instruments.

It is clear, however, that as things are at present, international agreement can only be secured for what may be termed reasonable concert-hall conditions, and until those conditions are such that the pitches of musical instruments are virtually free from temperature change, the working temperature will normally require to be specified. It seems probable from the above that a figure at or near $20^{\circ} \mathrm{C} .\left(68^{\circ} \mathrm{F}\right.$.) is likely to be acceptable to the majority of nations.

The indications are that an international conference on the question of musical pitch may be convened in 1939. It would accordingly be appreciated if those readers of NATURE who are interested in the general situation would be good enough to communicate with the Director, British Standards Institution, 28 Victoria Street, London, S.W.1. 